\title{
The Analysis of Local Fiscal Expenditure Inefficiencies
}

\author{
Dexiang Wang ${ }^{1}$ and Fei Xie ${ }^{1,2}$ \\ ${ }^{1}$ Economics and Management School, Wuhan University, 430072 Wuhan Hubei, China \\ ${ }^{2}$ First Auditing Division, Shanghai Municipal Bureau of Local Taxation, 200011 Shanghai, China
}

\begin{abstract}
Public expenditure efficiency plays an increasing important role in the process of establishment and perfection of public finance system. Corresponding indexes are selected to empirically analyze the efficiency of local government's public expenditure, which turned out to be not high. This paper pointed out the reasons why the efficiency isn't high, such as the disequilibrium of government's routine power and financial power, offside and absence of governments, and proposed some relevant suggestions.
\end{abstract}

Keywords. fiscal spending; local government; fiscal expenditure efficiency

\section{Introduction}

With the deepening of public finance reform in China, the government's leading role is growing in promoting social equity and achieving stable and sustainable development of regional economy. The Twelfth Five-year Plan for National Economic and Social Development of the People's Republic of China proposed that all levels of governments will continue increasing public spending, especially incline to ensure the people's basic livelihood to fundamentally realize the equalization of public service of different places. However, there are many problems behind the rapid growth of public financial investment. In the process of establishment and perfection of public finance system, public expenditure efficiency becomes more and more important which is the basic of government's public expenditure management activities and has the direct bearing on the success or failure of public finance construction.

Richard Musgrave (1959) proposed the definition of public expenditure. David Heald (1979) thought the domain of public expenditure should be decided by the routine power of all levels of government. S Devarajan, V Swaroop and Hengfu Zou (1996) considered that it is non-profit for the government to perform public functions which is aimed at remedying the market deficiency. Van den Eeckaut et al. (1993) and De Borger et al. (1994) said the governments in higher per capita income regions will lose control on costs. Athanassopoulos and Triantis (1998) said that the residents of the region with higher per capita income could improve the efficiency of fiscal expenditure. Worthington (2000) estimated the efficiency of urban public sector spending with random boundary method at first. Afonso and Fernandes (2008) evaluated the efficiency of fiscal spending of local governments in Portugal.

\section{Empirical study of public expenditure efficiency of local governments}

This paper selected some government departments to evaluate the efficiency of public expenditure, and the categories covered government administration, education, science, public health care, sports, social security benefits, and rural infrastructure and rural affairs. According to the difference between regional population bases, we will choose some indicators and divide the corresponding number of population. All the indicators are chosen and showed in table 1 below:

Table 1. Input-output indexes system of public expenditure of local governments.

\begin{tabular}{lll}
\hline Category & Input index & Output index \\
\hline Government administrative & Per capita government administrative management & Criminal cases per ten thousand persons \\
management & finance expenditure & Per capita education years \\
Education & Per capita education finance expenditure & Three patents grant for sci-tech per ten thousand persons \\
Scientific research & Per capita scientific research finance expenditure & Actual number of bed per ten thousand persons \\
Health care & Per capita health care finance expenditure & Per capita actual collection of books of public library \\
Recreation and sports & Per capita recreation and sports finance expenditure & Coverage ratio of social security \\
Social security benefit & Per capita social security benefit finance expenditure & Cond network density \\
Urban and rural infrastructure & Per capita infrastructure finance expenditure & Road networe \\
\hline
\end{tabular}


DEA, a data-oriented evaluation methodology, is a nonparametric efficiency estimate technology which applies the mathematics process of linear programming to evaluate relative efficiency of the same type of Decision Making Unit (DMU) with multi-input and multi-output. The theory is as follows: DEA builds the optimal productive frontier based on the input and output indicators of DMU and compares it with observing individual DMU behavior to get measured value of different DMU's efficiency.

Assume we evaluate the public expenditure efficiency of $\mathrm{N}$ local governments and the input is $\mathrm{m}$ and the output is $\mathrm{s}$ for each. For the ith local government's DMU, $X_{i}$ and $Y_{i}$ respectively indicate as its input column vector and output column, $X$ and $Y$ are the matrix-vectors of $(m \times n)$ and $(s \times n)$, and the ith DMU's public expenditure efficiency can be expressed as:

$$
\begin{aligned}
& \min \theta \\
& \text { s.t. } \sum_{i=1}^{m} \lambda_{i} X_{i} \leq \theta X_{0} \\
& \sum_{i=1}^{s} Y_{i} \lambda_{i} \geq \theta Y_{0} \\
& \sum_{i=1}^{n} \lambda_{i}=1 \\
& \lambda_{i} \geq 0 \quad i=1,2, \cdots, n
\end{aligned}
$$

$\theta$, the solution of linear programming, is the relative efficiency value of $D M U_{i}$, which is called technical efficiency. When $\theta=1$, it means DMU's technical efficiency is valid, and the input $X_{0}$ reaches optimal level under the condition that the original output $Y_{0}$ doesn't change; when $\theta<1$, the technical efficiency is in vain that means input $X_{0}$ can be reduced to a proper ratio to maintain original output $Y_{0}$.

This paper investigates the dynamic change trend of public expenditure efficiency of local governments in a continuous period. The postulated condition of estimation of relative efficiency for DEA is the production technology in unit interval doesn't change. In view of the possible changes in continuous time, there will be a deviation if compare the DMU efficiency values which are respectively got from different time quantum. However, it can be solved by Malmquist index and the form is as follows:

$M_{0}\left(Y_{t+1}{ }^{\prime} X_{t+1} Y_{t}{ }^{\prime} X_{t}\right)=\frac{d_{0}^{t+1}\left(X_{t+1}{ }^{\prime} Y_{t+1}\right)}{d_{0}^{t}\left(X_{t}^{\prime} Y_{t}\right)} \times\left[\frac{d_{0}^{t}\left(X_{t+1}{ }^{\prime} Y_{t+1}\right)}{d_{0}^{t+1}\left(X_{t+1}{ }^{\prime} Y_{t+1}\right)} \times \frac{d_{0}^{t}\left(X_{t}^{\prime} Y_{t}\right)}{d_{0}^{t+1}\left(X_{t}^{\prime} Y_{t}\right)}\right]^{1 / 2}$

In formula (2), $\left(X_{t+1}, Y_{t+1}\right)$ and $\left(X_{t}, Y_{t}\right)$ respectively shows the input-output vector quantity in $\mathrm{t}+1$ and $\mathrm{t}$ for DMU, and $M_{0}$ is Malmquist index which represents the productivity variation from $\mathrm{t}$ to $\mathrm{t}+1$. Malmquist productivity index can be broke up into the product of overall efficiency variation and technical variation and the former is the emphasis, which is the first half of formula (2).

The DEA model is first used to reckon the efficiency value of every DMU in base period and the Malmquist change rate from base period to second period. Multiply them to get the DEA efficiency value of DMU in second year, and all DEA efficiency values in different periods can be got by that analogy. The revised DEA efficiency algorithm has comparability in continuous time.

The paper regards nationwide 28 provincial governments $^{\mathrm{a}}$ as DMUs, and applies the DEA-Malmquist index method to estimate the public expenditure efficiency of each local government. The data in the paper come from China Statistical Yearbook, China Labour and Social Security Yearbook, China Population Statistics Yearbook, etc. in 2001-2013. The result showed that the public expenditure efficiency presented $\mathrm{V}$ type variation trend, and a transaction appeared in 2003. Before 2003, it presented downtrend while it presented uptrend after that and the reason is central government put forward public finance to accelerate transformation of public function and promote the management system construction of public expenditure for local governments. The nationwide average efficiency value is always under 0.9 , and there is still room for growth.

\section{Reasons for inefficiency of fiscal ex- penditure of local government}

\subsection{Mismatch between routine power and finan- cial power}

In the course of central financial system reform, the central government delegates the financial power and financial resources to local governments, which strengthens the ability of fiscal expenditure of local governments, and then increases the role of local governments in the economic and social development.

After tax sharing reform in 1994, the central government defined the range of function of local governments. With the clarity of functions, the local governments were responsible for the supply of local public goods, which enlarged their routine power so as to the increasing total amount of fiscal expenditure.

Although the routine power of local governments continued to expand, their financial power was reduced dramatically after reform. In order to enhance the ability of macro-control, the central government concentrated the financial power of local governments. It is necessary for partly concentration of local governments' financial. However, with the increasing delegation of local governments' routine power and excessive concentration of their fiscal revenue, the routine power of local governments is decentralized while their financial power is contrary, which directly leads the mismatching between them. Under the circumstances, it will be powerless for the local governments to improve the quantity and quality of public goods supply.

\subsection{Coexistence between offside and absence}

\footnotetext{
${ }^{\mathrm{a}}$ Three provincial governments of Chongqing, Tibet and Hainan aren't included.
} 
Offside and absence obviously exist in fiscal expenditure of local governments in China. Offside shows that local governments put the fiscal expenditure into the private goods area, and there are two main reasons:

On the one hand, because of the range adjustment of local governments' functions, the central government claimed that the local governments' fiscal expenditure should be gradually put into public goods, while the input of private goods must be reduced. However, in the private goods field, it is difficult and complex to reform of joint-stock system and bankruptcy liquidation for local state-owned enterprises because of the leftover problems under original planned economic system. Therefore, local governments undertake high costs of reform, which makes it hard for them to drop quickly and thoroughly out of the field of private goods, and results in the absence of investment of public goods.

On the other hand, thanks to backwardness of structural reform in the field of public goods, non-equivalence between investment right and responsibility and lack of sense of ability and supervision, local governments always enlarge the input of private goods to reach political achievements. Hence, they are reluctant to quit from the field of private goods in nature, which also leads to the absence.

Aforementioned offside of governments' fiscal expenditure surely will result in the absence of input of public goods. It mainly shows in under-investment of education and social insurance.

\subsection{Unsoundness of management and control mechanism}

Although the reform of control of local governments' fiscal expenditure just starts, its significance goes without saying. In fiscal expenditure, financial budget is the basis of governments' fiscal expenditure. It is not only a law which strictly stipulates local governments' fiscal expenditure, but also an effective method to control it.

Budget Law has been enacted and implemented in China, but the result isn't ideal: (1) budgeting of fiscal expenditure isn't refined enough; (2) budget constraint of fiscal expenditure is soft; (3) supervision of fiscal expenditure isn't strong. Hence, lack of supervision capability, countermeasure and corresponding penalty provision of illegal use of fiscal appropriation, and normalized supervision system, it will have an influence on effectiveness and authority of local finance department.

\subsection{Explosion of government size increases the burden on fiscal expenditure}

The local government size is expanding and more staffs need to support, which increases significantly its administration cost. It has become a key factor to unreasonable structure of local fiscal expenditure and indirectly reduced its efficiency.

The efficiency of local governments' fiscal expenditure is reflected in the administration expense. Intuitively, higher efficiency region has lower administration expense, while lower efficiency region has higher administration expense.

\subsection{Local government is lack of inherent pressure}

Firstly, local governments and officials incline generally to maximize the budget. In their public administration, the cost is always detached from benefit which lowers the efficiency of financial resources allocation. One is the government sector pays more attention to acquirement of fiscal fund instead of using effect; the other one is local government enlarges aimless supply regardless of real demand of people for public goods so as to the waste of financial resources; the last one is the output of local public goods is constant while the sector has an tendency to increase the budget which also results in waste. Since government monopolizes the real information of actual cost of public goods, it is hard to tell if the output achieves the Pareto Optimality.

Secondly, the government department and staff are evaluated and encouraged by if they obey the superior arrangement to the letter and toe the line instead of their performance. So it brings out the inefficiency of administration and increase of administrative cost to some extent.

Thirdly, from the traditional view, the local government is the only subject of local public goods. Its monopoly makes local government responsible for all local public goods. Under this situation, the local government and officials are unwilling to lower the cost and enhance the efficiency of fiscal expenditure because their investment organization lack of pressure of competition and incentive mechanism.

\section{Suggestion on improving efficiency of fiscal expenditure}

\subsection{Strengthen supervision of fiscal fund}

Strengthen supervision of fiscal fund and perfect related fiscal system including auditing system, budget and financial statement system, centralized treasury payment system, financial information disclosure system, government procurement system and so on. Continue to detail budget account, manage money matters according to law, reinforce the legislation and transparency of budget and final account and spare no effort to solve budgetary soft restricted problems and loopholes of system such as vague budget, poor implementation and unsound supervision. Concerning fiscal information disclosure system, the relevant information should open widely. Concerning government procurement system, the legislation should be strengthened, the procurement process must be normalized and sound supervision mechanism ought to be established lest the system becomes a mere formality. Concerning the auditing system of fiscal fund, it is not only the legality and compliance but also the effectiveness should be evaluated for the fiscal fund utilization. A rounded analysis must be carried out for the appropriation 
and using of fiscal fund by the audit on the basis of overall budgetary process.

\subsection{Effectively use fiscal fund}

Optimize the use procedure of fiscal fund to increase input-output ratio. Pay more attention to the effective use of fiscal fund in improvement of policy, management and technology. On subsidy methods, it can be turned from indirection to direction which can not only lessen misconduct and waste of fiscal fund caused by intermediate link, but also can use the fiscal fund for the subsidy object so as to strengthen its function. For the input, in order to avoid the crash expenditure in the end of the year, the randomness and unavailability of fiscal expenditure should be cut down. On the expenditure patterns, turn the consuming fiscal spending to investment expenditure. Concerning the management and technological level of fiscal fund project, widely use existing technology and adopt the latest management method to enhance the technical efficiency. In addition, consummate fiscal management system further, and reinforce the unified adjustment and control of the fund.

\subsection{Control the scale of fiscal expenditure}

The increasing scale of finance stems from what is called "tragedy of the commons" of fiscal budget, that means the budget fund processes the economic attribute of public resources and on account of the rigidity of budget outlays, all departments strives for the budget resources on increment, which results in excessive plunder of tax fund. The reason why the efficiency of fiscal expenditure is not high is that the public sectors and staffs are too much so the surge of administrative fees lowers the efficiency. First, precisely define the range of fiscal expenditure. Under the environment of market economy, the governmental macro-control must process certain boundaries. Its main function is to compensate for the deficiency of market which makes the range of governmental expenditure controlled. Second, according to the scope definition, the government should combine with the transform of fiscal function, weaken the expenditure of economic construction, call off the products and services which can be offered by market, retreat from some competitive fields and concentrate money to control key sectors of national economy and guide the development of emerging industry. Third, strictly control the fiscal consuming expense. At last, establish an effective total quantity control mechanism.

\section{References}

1. Musgrave R.A. The Theory of Public Finance: A Study in Public Economy. 1959.

2. Heald D. Public expenditure and public accountability [J]. Omega, 1979, (7):469-79.

3. Harold O. The Measurement of Productive Efficiency: Techniques and Applications: Techniques and Applications [M]. London: Oxford University Press, 1993.

4. De Borger B., Kerstens K. Moesen W. \& Vanneste J. Explaining differences in productive efficiency: An application to Belgian municipalities [J]. Public Choice, 1994, (80):339-58.

5. Devarajan S., Swaroop V. \& Zou H. The composition of public expenditure and economic growth [J]. Journal of Monetary Economics, 1996, (37):313-44.

6. Athanassopoulos A.D. \& Triantis K.P. Assessing aggregate cost efficiency and the related policy implications for Greek local municipalities [J]. Infor, 1998, (36):66-83.

7. Worthington A.C. Cost efficiency in Australian local government: A comparative analysis of mathematical programming and econometrical approaches $[\mathrm{J}] . \mathrm{Fi}$ nancial Accountability \& Management, 2000, (16): 201-23.

8. Afonso A. \& Fernandes S. Assessing and explaining the relative efficiency of local government [J]. The Journal of Socio-Economics, 2008, (37):1946-79. 